Thorax (1966), 21, 129.

\title{
Chylothorax after closure of a patent ductus arteriosus
}

\author{
M. S. GOT S M A N ${ }^{1}$ \\ From the Children's Hospital, Birmingham
}

Traumatic chylothorax has occurred after nearly every intrathoracic operation (Ross, 1961; Williams and Burford, 1964). If malignant disease and its operations are excluded, it is most common after splanchnicectomy (Hodge and Bridges, 1948), resection of coarctation of the aorta, and Blalock's anastomosis (Shumacker and Moore, 1951 ; Baffes and Potts, 1954). It is uncommon after ligation or transection of the ductus arteriosus, and few cases have been reported in the literature (Baffes and Potts, 1954 ; Vandecasteele and Soots, 1961).

We have observed traumatic chylothorax after transection of a persistently patent ductus arteriosus and will describe the favourable outcome with conservative management.

\section{CASE REPORT}

C. T. is an only child. A murmur was detected three weeks after birth. She had two serious episodes of acute bronchitis at the age of 10 and 12 months respectively. Apart from failure to thrive she was symptom-free. At the age of 16 months she weighed $14 \mathrm{lb} .\left(6 \cdot 35 \mathrm{~kg}\right.$.) and was $27 \frac{1}{2}$ in. $(70 \mathrm{~cm}$.) in height. Both height and weight were below the third percentile for chronological age. She had the typical physical signs of a large patent ductus arteriosus (clinical, E.C.G., and radiological), and this was confirmed by venous angiocardiography.

Operation was performed by Mr. L. D. Abrams on 3 June 1964, when she was 16 months old. A $0.75 \mathrm{~cm}$. ductus arteriosus was ligated and transected through a postero-lateral thoracotomy in the fourth left intercostal space (d'Abreu, 1956). The operation was straightforward without extensive dissection to mobilize the ductus. Intrathoracic bleeding did not occur.

For the first 24 hours after operation her clinical condition and chest radiograph were satisfactory. The following day mild swelling and surgical emphysema of the chest wall surrounding the incision were observed. There was a hazy opacity on the left side on 1Present address: The Cardiac Clinic, Groote Schuur Hospital,
Cape Town, South Africa the chest radiograph. When the pleural drainage tube was removed, $40 \mathrm{ml}$. of thin mucoid material was discharged under tension and was presumed to be a subcutaneous collection of fluid. A further chest radiograph on the third post-operative day showed an increased opacity in the left pleural cavity. The haemoglobin concentration had increased to $120 \%$ and the white cell count to 14,000 per c.mm.

The left-sided effusion accumulated rapidly. The same afternoon the child collapsed with a lowered blood pressure of $95 / 50 \mathrm{~mm}$. $\mathrm{Hg}$, a pulse rate of 140 per minute, and a respiratory rate of 40 per minute. She was cold, clammy, and cyanosed.

On the chest radiograph the left hemithorax was opaque. No air entry could be heard on auscultation. Despite the large pleural effusion she had a metabolic acidosis with a $p \mathrm{H}$ of $7 \cdot 33, \mathrm{PcO}_{2}$ of $32 \mathrm{~mm}$. $\mathrm{Hg}$, and base excess of $-8.5 \mathrm{mEq} / \mathrm{l}$. Chyle, $250 \mathrm{ml}$, was aspirated from the left pleural cavity and her clinical condition improved.

During the following five weeks the chest was aspirated eight times, and a total volume of $2,130 \mathrm{ml}$. of chyle was removed. Aspiration was performed only when a large effusion had accumulated and the child was distressed. The chyle was turbid, containing $3.5 \mathrm{~g}$. protein and $1.8 \mathrm{~g}$. total lipid per $100 \mathrm{ml}$. The serum electrolytes remained normal with a blood urea of $28 \mathrm{mg}$. $/ 100 \mathrm{ml}$. The plasma proteins fell to $5.7 \mathrm{~g}$./ $100 \mathrm{ml}$. (albumin $2.0 \mathrm{~g}$., globulin $3.7 \mathrm{~g}$.; reduction in alpha- and gamma-globulins), the total lipid to 650 mg. $/ 100 \mathrm{ml}$., and the cholesterol to $177 \mathrm{mg} . / 100 \mathrm{ml}$.

Digoxin was started when she collapsed initially and was continued during her stay in hospital. Sodium cloxacillin (125 mg. six-hourly orally) was given to prevent infection after the repeated aspirations. She had a small spike of temperature above $100^{\circ} \mathrm{F}$. on four occasions, but the fluid was always sterile on culture.

She was given a high protein/low fat diet. In view of the important loss of protein and lipid by aspiration, and the consequent low serum albumin and lipid, intravenous plasma and emulsified fat solutions ('Intralipid') were given $(1,340 \mathrm{ml}$. plasma, $1,200 \mathrm{ml}$. Intralipid).

Less frequent pleural aspiration was required and a smaller volume was removed on each occasion. At each aspiration all the chyle was removed, since 
aspiration was undertaken to reduce compression collapse of the underlying lung and to improve respiratory distress.

On this regime the child improved. At the time of discharge the total serum protein concentration was 6.5 g. $/ 100 \mathrm{ml}$. (albumin 3.46 g., globulin 3.1 g. ; normal alpha- and gamma-globulins). The serum total lipid had risen to $750 \mathrm{mg}$. $/ 100 \mathrm{ml}$. and the cholesterol to $232 \mathrm{mg} . / 100 \mathrm{ml}$.

After six weeks the child was discharged home with only a small residual chylothorax.

Two months later she was thriving with few residual physical signs. The final chest radiograph was normal.

\section{DISCUSSION}

Traumatic, post-surgical chylothorax was an unexpected complication of an otherwise orthodox ligation and transection of a persistently patent ductus arteriosus. The anatomy of the thoracic duct is variable. It usually ascends between the aorta and azygos vein slightly to the right side of the vertebral column. At the level of the fourth to sixth dorsal vertebrae the duct crosses to the left of the vertebral column and continues upwards, entering the superior mediastinum between the aortic arch and the left subclavian artery and the left side of the oesophagus. Wide anatomical variations may exist in all portions of the duct. Dual ducts and multiple anastomotic channels may occur (Davis, 1915 ; Williams and Burford, 1964). Normally the ductus arteriosus and thoracic duct are not related structures, so that accidental trauma may be a result of the duct crossing from right to left at a lower level, a variation in normal anatomy or accidental puncture of a normally situated duct.

The delayed onset of signs has been observed before (Randolph and Gross, 1957). This latent period seems to be the time necessary for the escaping chyle to accumulate sufficiently in the mediastinum to break through the pleura and enter the pleural cavity-a logical sequence in this patient.

Conservative therapy has been popular in managing traumatic lesions of the thoracic duct since the lesions often close spontaneously. Moreover, at operation the site of the lesion may be difficult to identify, particularly if fresh adhesions are present at the site of previous surgery (Baffes and Potts, 1954 ; Ross, 1961 ; Williams and Burford, 1964). In this patient conservative therapy was successful and the leak closed spontaneously.

Two forms of active therapy were undertaken. Mechanical compression of the left lung by the rapidly accumulating chylothorax was relieved by frequent aspiration of the pleural cavity. This was undertaken reluctantly, since fluid, electrolytes, protein, and fat were removed from an already depleted child. Aspiration was undertaken only when the child was distressed. For the first two weeks aspirations were required every second or third day, but later this was required less frequently until the reaccumulation of fluid stopped.

Intravenous fluid therapy was probably lifesaving. Initially, a rapid accumulation of fluid in the left pleural cavity led to hypovolaemic shock with hypotension, tachycardia, and haemoconcentration during the acute stage. Later, after the pleural cavity had been aspirated repeatedly, hypoalbuminaemia and hypolipidaemia followed with depletion of the alpha- and gamma-globulin fractions. The nutritional depletion syndrome was treated with a high protein/low fat diet since chylomicrons absorbed from the gastro-intestinal tract are lost into the pleural cavity (Ross, 1961). Gastro-intestinal aspiration was not used. Additional intravenous plasma and soluble fat emulsion solutions were given to treat and prevent further protein and lipid depletion. Chyle has a composition similar to that of plasma, but a higher fat content. Therefore the pleural aspirate was replaced by an equal volume of intravenous fluid, given half as plasma and half as fat solution. The latter was also a simple method of infusing a solution of high calorie value.

\section{SUMMARY}

A 16-month-old child, who had ligation and transection of a persistently patent ductus arteriosus, developed a traumatic chylothorax after operation.

This was treated conservatively with repeated aspiration, only to prevent compression collapse of the lung. A low fat/high protein diet was given in an attempt to prevent fat loss in the chyle, but the most important facet of management was intravenous reconstituted human plasma and emulsified fat, which improved the severe hypoalbuminaemia and hypolipidaemia.

The child recovered completely without further surgery and is now alive and well with a clinically normal left lung.

I am grateful to Dr. C. G. Parsons for encouragement, and to Mrs. J. H. Coull for secretarial assistance.

\section{REFERENCES}

Baffes, T. G., and Potts, W. J. (1954). Postoperative chylothorax. Ann. Surg., 139, 501.

d'Abreu, A. L. (1956). Persistent ductus arteriosus. In Operative Surgery, p. 126. Ed. Rob, C., and Smith, R. Vol. 3, Part 5, Butterworth, London.

Davis, H. K. (1915). A statistical study of the thoracic duct in man. Amer. J. Anat., 17, 211. 
Hodge, G. B., and Bridges, H. (1948). Surgical management of thoracic duct injuries: an experimental study with clinical application. Surgery, 24, 805.

Randolph, J. G., and Gross, R. E. (1957). Congenital chylothorax. Arch. Surg., 74, 405.

Ross, J. K. (1961). A review of the surgery of the thoracic duct. Thorax, 16, 12 .
Shumacker H. B., and Moore, T. C. (1951). Surgical management of traumatic chylothorax. Surg. Gynec. Obstet., 93, 46.

Vandecasteele, J., and Soots, G. (1961). Chylothorax après cure chirurgicale de canal artériel persistant. Guérison par traitement médical. Lille chir., 16, 93.

Williams, K. R., and Burford, T. H. (1964). The management of chylothorax. Ann. Surg., 160, 131. 